\title{
Economic evaluation of a behavioral intervention versus brief advice for substance use treatment in pregnant women: results from a randomized controlled trial
}

\author{
Xiao $\mathrm{Xu}^{1 *}$, Kimberly A. Yonkers ${ }^{2}$ and Jennifer Prah Ruger ${ }^{3}$
}

\begin{abstract}
Background: Substance use in pregnancy is associated with severe maternal and fetal morbidities and substantial economic costs. However, few studies have evaluated the cost-effectiveness of substance use treatment programs in pregnant women. The purpose of this study was to evaluate the economic impact of a behavioral intervention that integrated motivational enhancement therapy with cognitive behavioral therapy (MET-CBT) for treatment of substance use in pregnancy, in comparison with brief advice.
\end{abstract}

Methods: We conducted an economic evaluation alongside a clinical trial by collecting data on resource utilization and performing a cost minimization analysis as MET-CBT and brief advice had similar effects on clinical outcomes (e.g., alcohol and drug use and birth outcomes). Costs were estimated from the health care system's perspective and included intervention costs, hospital facility costs, physician fees, and costs of psychotropic medications from the date of intake assessment until 3-month postpartum. We compared effects of MET-CBT on costs with those of brief advice using Wilcoxon rank sum tests.

Results: Although the integrated MET-CBT therapy had higher intervention cost than brief advice (median $=\$ 1297$ / participant versus $\$ 303 /$ participant, $p<0.01$ ), costs of care during the prenatal period, delivery, and postpartum period, as well as for psychotropic medications, were comparable between the two groups (all $p$ values $\geq 0.55$ ). There was no statistically significant difference in overall cost of care (median total cost $=\$ 26,993 /$ participant for MET-CBT versus $\$ 27,831 /$ participant for brief advice, $p=0.90$ ).

Conclusions: The MET-CBT therapy and brief advice resulted in similar clinical outcomes and overall medical costs. Further research incorporating non-medical costs, targeting women with more severe substance use disorders, and evaluating the impact of MET-CBT on participants' quality of life will provide additional insights.

Trial registration: ClinicalTrials.gov NCT00227903. Registered 27 September 2005.

Keywords: Cost minimization analysis, Economic evaluation, Substance use, Pregnancy, Randomized controlled trial

\footnotetext{
* Correspondence: xiao.xu@yale.edu

'Department of Obstetrics, Gynecology and Reproductive Sciences, Yale

School of Medicine, 310 Cedar Street, LSOG 205B, New Haven, CT 06520,

USA

Full list of author information is available at the end of the article
} 


\section{Background}

Use of illicit drugs, alcohol and tobacco during pregnancy is associated with severe maternal and fetal morbidities, such as placental abruption, birth defects, preterm birth, drug withdrawal syndromes and longerterm developmental problems [1-4]. Illicit drug use by pregnant women also increases their risk for human immunodeficiency virus (HIV) infection and subsequent risk for vertical transmission to infants $[1,5]$.

The rate of substance use in pregnancy is high and it is associated with substantial economic costs. National survey data showed that in the U.S., 5.9, 8.5 and $15.9 \%$ of pregnant women 15-44 years of age reported current use of illicit drugs, alcohol and cigarettes, respectively, in 2011-2012 [6]. Treatment for opioids-exposed newborns cost \$70.6-\$112.6 million in the U.S. in 2009 [7], and the average lifetime cost for a newborn with fetal alcohol syndrome was estimated to be $\$ 2.0$ million in 2002 [8].

Although pregnant substance users have unique medical, psychological and social care needs, few studies have evaluated substance use treatment programs tailored to pregnant women and the limited number of studies available have targeted particular substances, such as nicotine or alcohol alone $[9,10]$, rather than women who use a variety of substances which is common in pregnant substance users [11]. Moreover, literature on the economic impact of these interventions is sparse [12], despite growing concerns about health care spending. Their clinical effectiveness needs to be carefully weighed against cost consequences in order to deliver high-value care.

In this study, we conducted an economic evaluation of an innovative intervention integrating motivational enhancement therapy with cognitive behavioral therapy (MET-CBT), in comparison with brief advice, designed for reducing substance use and HIV risk behaviors in pregnant women who use an array of substances. The findings will inform future allocation of resources for addressing substance use in pregnancy.

\section{Methods}

\section{Intervention and participants}

This study was an economic evaluation alongside a randomized controlled trial (RCT), i.e., Therapeutic Substance Abuse Treatment in Pregnancy-1 (PRIDE-P) trial. Details about the design, intervention, methods, and main clinical outcomes of the PRIDE-P trial are reported elsewhere [13]. Briefly, an MET-CBT intervention was designed to reduce substance use in pregnancy, decrease risky sexual behaviors, and improve birth outcomes. Pregnant women who used substances (alcohol, marijuana, cocaine, or stimulants but not solo use of opiates or nicotine) during the 28 days prior to screening or scored at least a " 3 " on the modified TWEAK
(Tolerance, Worried, Eye-openers, Amnesia, K[C] Cut Down) screening test were eligible if they were 16 years of age or older and less than 28 weeks of gestation at the time of screening [13-15]. Patients whose primary substance was opioid or nicotine were excluded because methadone maintenance programs are the established treatment for patients with opioid use disorders and the study sites already had standard nicotine treatment protocols at the time of this study. Participants were randomly assigned to receive either the MET-CBT intervention or brief advice.

Women assigned to the MET-CBT group received one-on-one therapy from a trained nurse therapist at prenatal visits with optional booster visits after delivery (average number of sessions completed $=5.2$ ). Each session lasted for about $30 \mathrm{~min}$. Topics covered included: motivational enhancement, functional analysis (non-drug activities and triggers/patterns), safe sexual behavior, communication skills, relapse prevention, and problemsolving skills.

For participants assigned to receive brief advice, their routine obstetric providers provided brief guidance about the risks of substance use, importance of abstinence, and benefit of seeking drug and alcohol treatment outside of the prenatal setting (average number of sessions $=7.2$ ). This discussion occurred within the routine prenatal/postpartum visits and each lasted for about $1 \mathrm{~min}$.

A total of 168 study participants were recruited from two hospital-based reproductive health clinics between June 2006 and July 2010 [13]. Only one study site was able to provide complete cost data; hence, our analysis focused on the subset of participants who received prenatal care and delivered at this site in order to perform a comprehensive economic evaluation. This resulted in an analytical sample size of 112 participants, of which 60 were randomized to MET-CBT and 52 received brief advice.

\section{Clinical effectiveness}

Results on clinical effectiveness of the integrated METCBT therapy, relative to brief advice, in the PRIDE-P trial are detailed elsewhere [13]. Briefly, participants were assessed at baseline, delivery, and 3-month postpartum. The primary outcome measure for clinical effectiveness was the percentage of days that a participant used alcohol or any drug during the prior 28 days $[13,16]$. Secondary outcomes included whether the participant was abstinent from substances (alcohol and drugs) according to self-report, urine toxicology test, or combined self-report and urine toxicology test, respectively; whether she was abstinent from alcohol according to breathalyzer tests; the Addiction Severity Index (ASI) [17] composite scores for alcohol and drug use; 
participants' sexual behaviors; and birth outcomes. Because there were no statistically significant treatment effects on primary or secondary clinical outcomes [13], the economic evaluation constituted a cost minimization analysis wherein, given similar effectiveness, we assessed which intervention was associated with lower costs.

\section{Cost}

Economic evaluation was conducted from the health care system's perspective. Measurement of costs included intervention costs, hospital facility costs, physician fees, and costs of psychotropic medications. Timeframe of the cost analysis began from the date of intake assessment until 3-month postpartum. Because this timeframe was less than 1 year, no discounting was needed. Intervention costs were determined using a micro-costing technique taking into consideration the quantity and unit price of all inputs used for the design and implementation of the MET-CBT intervention and brief advice [18]. Research-induced costs during the intervention (e.g., staff time spent on data entry) were excluded. Data on hospital facility costs were obtained from the institutional accounting database and therefore reflected actual medical resources consumed by participants and their newborns at each encounter (rather than charges or reimbursements). Physician costs were estimated based on actual payments received using data from a billing database for professional fees at the study site. Collectively, these hospital facility costs and physician costs encompassed all medical care services received by participants and their newborns at the study site from intake assessment until 3-month postpartum, including pregnancy-related as well as other medical services. To help elucidate the economic impact of the study interventions by phase of care, we categorized costs according to the time period when they occurred (i.e., prenatal period, labor and delivery, and postpartum period) and stratified by care for the mother versus the newborn. In addition, we reviewed medical records and obtained information on name, dose, frequency and duration of psychotropic medications used by participants during the study period. Average wholesale prices from Red Book Drug Topics [19] were used to estimate the cost of medications. Costs occurring in different years were inflation adjusted to 2012 U.S. dollars using the medical care component of consumer price index [20].

\section{Statistical analysis}

We used non-parametric Wilcoxon rank sum test for all comparisons of costs between MET-CBT and brief advice due to skewed distribution of cost data. Four participants had otherwise complete data but lacked information on physician cost for their labor and delivery hospitalization. For them, we applied a diagnosis- related group (DRG)-specific, average physician cost to hospital facility cost ratio (whenever feasible) or intervention group-specific average physician cost for labor and delivery based on the rest of the sample. Participants with other types of missing data (e.g., lacked data on physician costs entirely) were excluded from the primary analysis. In all statistical tests, $p$ values less than 0.05 were considered statistically significant.

In a sensitivity analysis, we included participants with missing costs by imputing their values using sample average costs from their corresponding intervention group (MET-CBT versus brief advice), setting (physician cost, hospital facility cost, versus medication cost), and time period (prenatal, labor and delivery, versus postpartum) or based on DRG-specific, average physician cost to hospital facility cost ratio (when feasible). For missing data on costs of psychotropic medications, we imputed the value using intervention group-specific average medication cost. In addition, three participants had twin pregnancies. As these pregnancies were substantially more expensive which might unduly influence comparison of costs due to the relatively small sample size, we conducted another sensitivity analysis focusing on participants with singleton births only.

\section{Results}

\section{Participant characteristics}

Participants' mean age was 25.1 years (standard deviation $=6.1)($ Table 1$)$. Over half $(53.2 \%)$ were black, and 25.9\% were Hispanic. Thirty-five percent had less than high school education, and most participants (94.6\%) had Medicaid coverage. Marijuana was the most frequently reported primary substance, followed by alcohol and cocaine. Over half of the participants (51.8\%) reported ever regularly using more than one substance, and $32.1 \%$ of the participants were determined as alcohol/drug abuse or dependent according to the MiniInternational Neuropsychiatric Interview (MINI) [21]. Average gestation age at the time of enrollment was 20.1 weeks.

\section{Costs}

Intervention cost was significantly higher for METCBT than for brief advice (median $=\$ 1297 /$ participant versus $\$ 303 /$ participant, $p<0.01)$ because of its higher set-up costs and longer session duration (Table 2) [18]. This difference, however, was overshadowed by the substantial medical costs that occurred during the period of pregnancy, delivery, and postpartum. The median per participant cost during prenatal, delivery and postpartum period was $\$ 6339$, $\$ 15,493$, and $\$ 1272$, respectively, for participants receiving MET-CBT, compared with \$6591, \$15,175, and $\$ 1254$, respectively, for participants receiving 
Table 1 Patient characteristics at baseline

\begin{tabular}{|c|c|c|c|}
\hline Characteristics & $\begin{array}{l}\text { Overall } \\
(n=112)\end{array}$ & $\begin{array}{l}\text { Brief Advice } \\
(n=60)\end{array}$ & $\begin{array}{l}\text { MET-CBT } \\
(n=52)\end{array}$ \\
\hline Age (in years) & $25.1 \pm 6.1$ & $25.4 \pm 5.8$ & $24.8 \pm 6.4$ \\
\hline \multicolumn{4}{|l|}{ Race } \\
\hline White & $36(32.4 \%)$ & $19(32.2 \%)$ & $17(32.7 \%)$ \\
\hline Black & $59(53.2 \%)$ & $31(52.5 \%)$ & $28(53.8 \%)$ \\
\hline Other & $16(14.4 \%)$ & $9(15.3 \%)$ & $7(13.5 \%)$ \\
\hline \multicolumn{4}{|l|}{ Hispanic ethnicity } \\
\hline Yes & $29(25.9 \%)$ & $17(28.3 \%)$ & $12(23.1 \%)$ \\
\hline No & $83(74.1 \%)$ & $43(71.7 \%)$ & $40(76.9 \%)$ \\
\hline \multicolumn{4}{|l|}{ Education (in years) } \\
\hline$<12$ & 39 (35.1\%) & $20(33.3 \%)$ & 19 (37.3\%) \\
\hline 12 & $42(37.8 \%)$ & $20(33.3 \%)$ & $22(43.1 \%)$ \\
\hline $13-15$ & $25(22.5 \%)$ & $16(26.7 \%)$ & $9(17.7 \%)$ \\
\hline$\geq 16$ & $5(4.5 \%)$ & $4(6.7 \%)$ & $1(2.0 \%)$ \\
\hline \multicolumn{4}{|l|}{ Type of insurance/payer } \\
\hline Medicaid & $106(94.6 \%)$ & $54(90.0 \%)$ & $52(100.0 \%)$ \\
\hline Other & $6(5.4 \%)$ & $6(10.0 \%)$ & $0(0.0 \%)$ \\
\hline \multicolumn{4}{|l|}{ Parity } \\
\hline 0 & $42(37.5 \%)$ & $22(36.7 \%)$ & $20(38.5 \%)$ \\
\hline 1 & $34(30.4 \%)$ & $21(35.0 \%)$ & $13(25.0 \%)$ \\
\hline$\geq 2$ & $36(32.1 \%)$ & $17(28.3 \%)$ & 19 (36.5\%) \\
\hline $\begin{array}{l}\text { Gestation age at time of } \\
\text { enrollment, weeks }\end{array}$ & $20.1 \pm 7.2$ & $20.3 \pm 7.3$ & $20.0 \pm 7.2$ \\
\hline \multicolumn{4}{|l|}{ Primary drug } \\
\hline Alcohol & $36(32.1 \%)$ & $18(30.0 \%)$ & $18(34.6 \%)$ \\
\hline Cocaine & $23(20.5 \%)$ & $12(20.0 \%)$ & $11(21.2 \%)$ \\
\hline Marijuana & $44(39.3 \%)$ & $24(40.0 \%)$ & $20(38.5 \%)$ \\
\hline Other & 9 (8.0\%) & $6(10.0 \%)$ & $3(5.8 \%)$ \\
\hline \multicolumn{4}{|l|}{$\begin{array}{l}\text { Ever regularly used more } \\
\text { than one substance }\end{array}$} \\
\hline Yes & 57 (51.8\%) & 33 (56.9\%) & $24(46.2 \%)$ \\
\hline No & $53(48.2 \%)$ & 25 (43.1\%) & $28(53.8 \%)$ \\
\hline \multicolumn{4}{|l|}{$\begin{array}{l}\text { MINI drug/alcohol } \\
\text { abuse/dependence }\end{array}$} \\
\hline Yes & 36 (32.1\%) & $23(38.3 \%)$ & $13(25.0 \%)$ \\
\hline No & 76 (67.9\%) & 37 (61.7\%) & 39 (75.0\%) \\
\hline
\end{tabular}

MET-CBT motivational enhancement therapy with cognitive behavioral therapy, MINI Mini-International Neuropsychiatric Interview. Statistics were reported as n (\%) or mean \pm standard deviation. Percentages may not add up to $100 \%$ due to rounding

brief advice (all $p$ values $\geq 0.55$ ). Costs of psychotropic medications were also similar between the two groups (median $=\$ 124$ versus $\$ 136, p=0.70$ ). Overall, there was no statistically significant difference in total cost of care for participants between the two groups (median $=\$ 26,993 /$ participant in MET-CBT versus $\$ 27,831 /$ participant in brief advice, $p=0.90$ ).
Distributions of costs were right skewed as a small number of participants incurred high costs. For example, 20 mothers $(17.9 \%)$ stayed in hospital for longer than 4 days; and of the 114 newborns with known length of stay (including 3 pairs of twins), 24 (21.1\%) were admitted for more than 10 days. As a result, mean overall cost was much higher than the median (mean $=\$ 43,294 /$ participant and \$47,693/participant for MET-CBT and brief advice, respectively). Maternal and newborn hospital stay for delivery accounted for the largest share of the overall cost $71.1 \%$ for the MET-CBT group and $73.6 \%$ for the brief advice group), followed by care received during the prenatal period (19.4 and 16.9\% for MET-CBT and brief advice, respectively) (Fig. 1).

Similar results were found in sensitivity analyses when only singleton births were included and when participants with missing data were included with imputed values. Median per participant cost was $\$ 26,817$ for MET-CBT versus $\$ 27,537$ for brief advice $(p=0.82)$ and $\$ 26,314$ for MET-CBT versus $\$ 27,537$ for brief advice ( $p=$ 0.97), respectively (Table 3 ).

\section{Discussion}

Drawing on data from pregnant women who used substances and participated in the PRIDE-P trial, we conducted an economic evaluation of a novel behavioral intervention aimed to reduce substance use and HIV risk behaviors and improve birth outcomes. There was no statistically significant difference in main clinical outcomes between the MET-CBT and brief advice groups [13]. Our cost minimization analysis showed that the overall cost of care was similar between the two groups, and was primarily influenced by labor and delivery cost.

One strength of this study is our comprehensive measurement of costs associated with the care of pregnant women, including intervention costs, costs during the prenatal period, and maternal and newborn costs up to 3 months postpartum, as well as both hospital facility costs and physician costs. In contrast, prior economic evaluations of substance use programs for pregnant women were often limited to drug treatment costs or selected care components (e.g., neonatal intensive care unit costs) [22-25]. Few have assessed the impact of intervention on overall maternal and newborn costs. In addition, by conducting an economic evaluation in the context of a randomized trial, we were able to rigorously assess the financial consequences of the intervention as potential impact of unobserved confounding factors was minimized. In contrast, previous studies evaluating the economic impact of substance use treatment programs in pregnancy were largely based on non-randomized designs limiting their ability to draw causal inferences [22-27]. 
Table 2 Comparison of per participant costs between brief advice and integrated motivational enhancement and cognitive behavioral therapy

\begin{tabular}{|c|c|c|c|c|c|}
\hline \multirow[t]{2}{*}{ Cost Category } & \multicolumn{2}{|c|}{ Brief Advice $(n=58)$} & \multicolumn{2}{|c|}{ MET-CBT $(n=48)$} & \multirow[t]{2}{*}{$P$ value } \\
\hline & Median & (Interquartile range) & Median & (Interquartile range) & \\
\hline Intervention & $\$ 303$ & $(\$ 264-\$ 329)$ & $\$ 1297$ & $(\$ 1178-\$ 1491)$ & $<0.01$ \\
\hline Prenatal period & $\$ 6591$ & $(\$ 4819-\$ 9909)$ & $\$ 6339$ & $(\$ 3436-\$ 9977)$ & 0.55 \\
\hline \multicolumn{6}{|l|}{ Labor and delivery } \\
\hline Mother & $\$ 9399$ & $(\$ 7664-\$ 11,745)$ & $\$ 9516$ & $(\$ 7101-\$ 12,113)$ & 0.91 \\
\hline Baby & $\$ 3611$ & $(\$ 2410-\$ 18,816)$ & $\$ 3708$ & $(\$ 2219-\$ 24,704)$ & 0.88 \\
\hline Mother + Baby & $\$ 15,175$ & $(\$ 11,194-\$ 32,926)$ & $\$ 15,493$ & $(\$ 10,352-\$ 33,507)$ & 0.94 \\
\hline \multicolumn{6}{|c|}{ 3-month postpartum period } \\
\hline Mother & $\$ 385$ & $(\$ 225-\$ 763)$ & $\$ 657$ & $(\$ 258-\$ 1196)$ & 0.12 \\
\hline Baby & $\$ 757$ & $(\$ 235-\$ 1278)$ & $\$ 820$ & $(\$ 394-\$ 1275)$ & 0.63 \\
\hline Mother + Baby & $\$ 1254$ & $(\$ 775-\$ 2434)$ & $\$ 1272$ & $(\$ 818-\$ 2782)$ & 0.65 \\
\hline Medication & $\$ 136$ & $(\$ 0-\$ 194)$ & $\$ 124$ & $(\$ 0-\$ 187)$ & 0.70 \\
\hline Total & $\$ 27,831$ & $(\$ 19,694-\$ 48,273)$ & $\$ 26,993$ & $(\$ 21,240-\$ 45,289)$ & 0.90 \\
\hline
\end{tabular}

six participants were excluded from primary analysis due to missing cost data. MET-CBT motivational enhancement therapy with cognitive behavioral therapy

Our study suggests that health care for substance using women and their newborns is costly. This finding is consistent with other studies. For example, Whiteman et al. [28] reported that hospital facility cost alone averaged $\$ 5616$ for pregnancy-related hospitalizations for women with opioid use in the U.S. during 1998-2009. Fingar et al. [29] also showed that in 2012, hospital facility cost for newborn stays related to substance use averaged $\$ 19,684$, compared to $\$ 4500$ for other newborns. One recent study by Goler et al [30] assessed costs of care for women receiving Early Start, an integrated prenatal intervention providing one-to-one counseling to pregnant women at risk for substance use [31]. Average cost of maternal and newborn care from prenatal until 1 year postpartum totaled $\$ 20,644$ per participant, compared to $\$ 27,812$ per non-participant substance user. Cost savings from medical care more than offset the program implementation cost [30]. Our cost estimates may be somewhat higher than these studies because a large proportion of participants in our study were

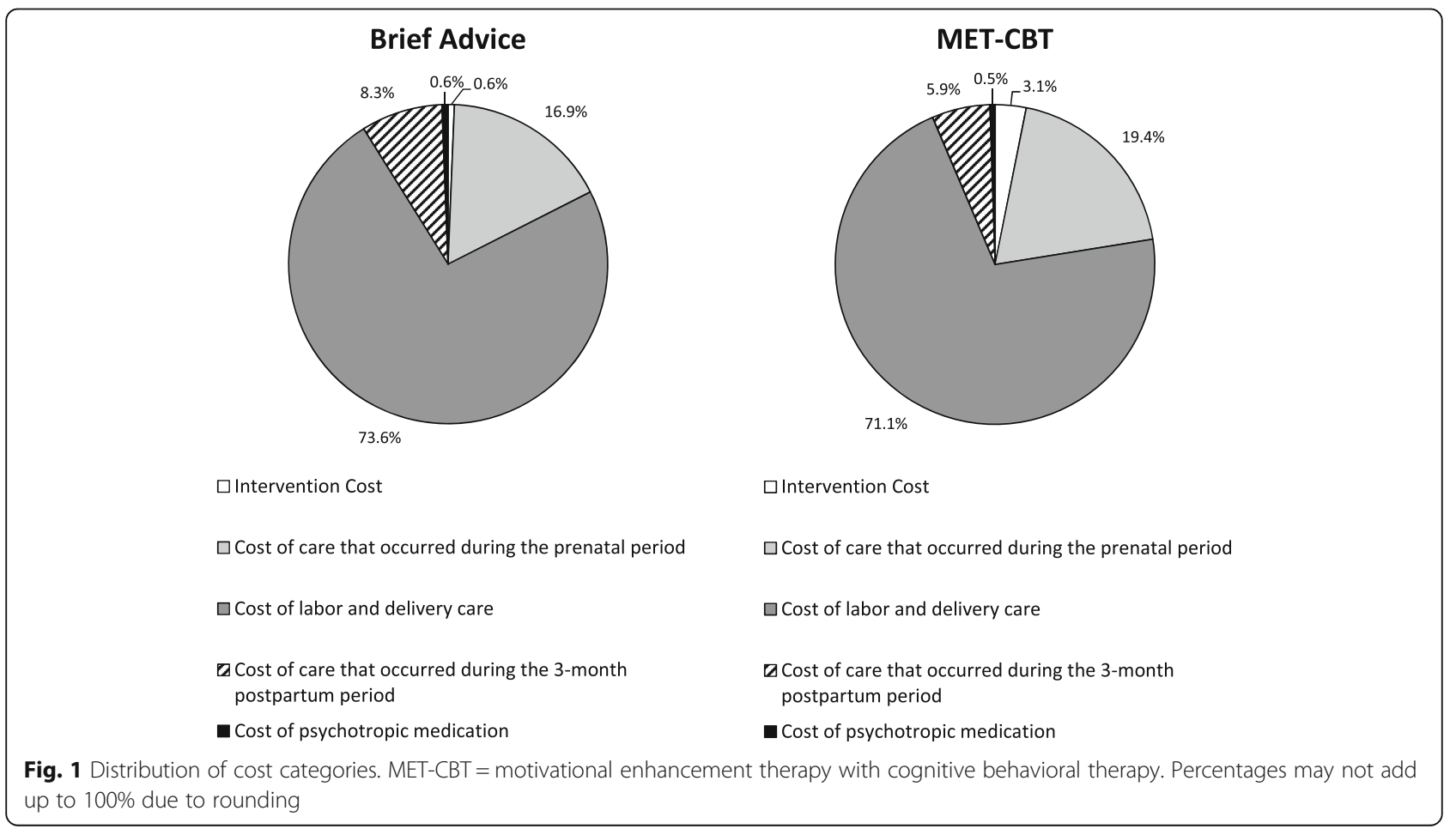


Table 3 Sensitivity analyses of per participant costs between brief advice and integrated motivational enhancement and cognitive behavioral therapy

\begin{tabular}{|c|c|c|c|c|c|}
\hline \multirow[b]{2}{*}{ Analysis } & \multicolumn{2}{|c|}{ Brief Advice } & \multicolumn{2}{|l|}{ MET-CBT } & \multirow[t]{2}{*}{$P$ value } \\
\hline & Median & (Interquartile Range) & Median & (Interquartile Range) & \\
\hline Base case analysis & $\$ 27,831$ & $(\$ 19,694-\$ 48,273)$ & $\$ 26,993$ & $(\$ 21,240-\$ 45,289)$ & 0.90 \\
\hline Limiting to singleton births & $\$ 27,537$ & $(\$ 19,354-\$ 45,131)$ & $\$ 26,817$ & $(\$ 21,070-\$ 44,172)$ & 0.82 \\
\hline Including participants with missing data (via imputation) & $\$ 27,537$ & $(\$ 18,891-\$ 47,519)$ & $\$ 26,314$ & $(\$ 20,538-\$ 43,914)$ & 0.97 \\
\hline
\end{tabular}

MET-CBT motivational enhancement therapy with cognitive behavioral therapy

polysubstance users and might be less healthy than patients in other studies. For example, $16.5 \%$ of our sample participants delivered preterm versus $7.7-15.4 \%$ in the various groups of substance users in Goler et al. [30]. In addition, we included costs associated with all medical services delivered during the study period, including those that were not directly pregnancy-related. This is to fully capture the impact of our study intervention which might improve participants' health behavior and hence have broader impact on resource utilization.

Our data from the PRIDE-P trial showed that compared with brief advice, MET-CBT did not reduce overall medical costs up to 3-month postpartum. Several factors may explain this lack of a significant difference. First, pregnancy itself may substantially affect women's health behavior, confounding and overshadowing the effect of MET-CBT. Second, many participants in our sample had relatively low substance use at baseline. Information provided in the brief advice intervention, including informing women of the adverse health impact of substance use (on both the mother and the fetus) and where additional treatment could be received, may be sufficient for these patients, making it difficult to observe the additional benefit of MET-CBT. Third, we designed MET-CBT as a one-on-one therapy to best match existing prenatal care at the study sites. This format is more costly than group therapy.

Further research assessing MET-CBT in patients with more severe substance use disorders or examining similar interventions in a group therapy setting will be informative. More research on the impact of similar psychotherapy on women's overall quality of life will also be informative as participants may experience improved well-being and social support despite lack of significant improvement in substance use. In addition, the PRIDE-P trial suggested a trend toward a reduction in preterm birth by MET-CBT as compared to brief advice (preterm birth rate $=10 \%$ versus $20 \%$, $p=0.08)$ although the study was not powered to assess this outcome [13]. Future studies with larger sample sizes testing the potential benefit of MET-CBT intervention in reducing preterm birth and the associated cost implications will provide additional insights.

This study has several limitations. First, our data were based on an RCT at a single study site. The findings may not be generalizable to all pregnant women who use substance or receive care elsewhere. Second, we estimated medical costs occurring within the study institution. Participants could have received care elsewhere which was not captured in our cost estimates. Third, physician cost data were unattainable at one of the study sites, precluding us from including all PRIDE-P trial participants in this analysis and reducing our statistical power for detecting differences between groups. Comparison between the two study sites also suggested that participants in our analysis were more likely to report marijuana as their primary substance (as opposed to alcohol at the other site) and a higher proportion of them were drug/alcohol abuse or dependent. However, data on hospital facility costs were available at both sites. Comparison of hospital facility costs between MET-CBT and brief advice groups at the other study site suggested no statistically significant difference either, corroborating our main findings. Finally, we were unable to perform the economic evaluation from a societal perspective as data on participants' transportation costs and productivity loss were only collected for intervention visits but not available for other medical encounters. Likewise, we did not have data on costs associated with legal services or child custody that often occur with substance use and can be costly. Future studies incorporating non-medical costs and longer follow-up times would be informative.

\section{Conclusions}

Substance use in pregnancy remains an important issue in obstetric care. Identifying cost-effective treatment options not only benefits the mother and her family, but also society. Our analysis of data from the PRIDE-P trial found that, compared with brief advice, a behavioral intervention integrating MET and CBT had similar effect on substance use and birth outcomes [13], and did not reduce overall medical costs up to 3-month postpartum. Continued effort to compare MET-CBT in patients with more severe substance use disorders or in different formats (e.g., group therapy) and to evaluate its impact on participants' quality of life will further inform the potential role of behavioral interventions in managing substance use in pregnancy. Future research should also assess the potential benefit of brief advice itself in promoting abstinence in substance users. 


\section{Abbreviations}

ASI: Addiction Severity Index; DRG: Diagnosis-related group; HIV: Human immunodeficiency virus; MET-CBT: Motivational enhancement therapy with cognitive behavioral therapy; MINI: Mini-International Neuropsychiatric Interview; PRIDE-P: Therapeutic Substance Abuse Treatment in Pregnancy-1; RCT: Randomized controlled trial; STIs: Sexually transmitted infections; TWEAK: Tolerance, Worried, Eye-openers, Amnesia, K[C] Cut Down

\section{Acknowledgements}

We thank Heather Howell, Brian Karsif, and Eliana B. Cohen for their assistance with this study. Preliminary results from this study were presented at the International Health Economics Association 10th World Congress in Dublin, Ireland, July 13-16, 2014.

\section{Funding}

This research was supported by grants from the National Institutes of Health (National Institute on Drug Abuse grants R01DA025555 and R01DA019135). JPR was also supported by the Patrick and Catherine Weldon Donaghue Medical Research Foundation. Funders had no role in study design; in the collection, analysis or interpretation of data; in the writing of the report; or in the decision to submit the article for publication.

\section{Availability of data and materials}

The datasets generated and analyzed in this study cannot be shared because they contain sensitive clinical and financial information and it is not feasible at this time to obtain informed consent for data sharing from participants.

\section{Authors' contributions}

XX participated in the collection of cost data, performed data analysis, and drafted the manuscript. KAY conceptualized, designed, and implemented the PRIDE-P trial, assisted in the collection of cost data, and reviewed and revised the manuscript. JPR conceptualized and designed the economic evaluation, collected cost data alongside the PRIDE-P trial, contributed to the analysis and interpretation of data, and reviewed and revised the manuscript. JPR was the principal investigator of the National Institute on Drug Abuse grant R01DA025555 that provided primary funding for this study. All authors read and approved the final manuscript.

\section{Competing interests}

The authors declare that they have no competing interests.

\section{Consent for publication}

Not applicable.

\section{Ethics approval and consent to participate}

This study was approved by Yale University Human Investigation Committee (HIC \# 0402026466) and Bridgeport Hospital Institutional Review Board (IRB \# 010502). Informed consent was obtained from all study participants

\section{Author details}

${ }^{1}$ Department of Obstetrics, Gynecology and Reproductive Sciences, Yale School of Medicine, 310 Cedar Street, LSOG 205B, New Haven, CT 06520, USA. ${ }^{2}$ Department of Psychiatry, Yale School of Medicine, New Haven, CT, USA. ${ }^{3}$ Department of Medical Ethics and Health Policy, Perelman School of Medicine, The Leonard Davis Institute of Health Economics, University of Pennsylvania, Philadelphia, PA, USA.

Received: 7 October 2015 Accepted: 28 February 2017

Published online: 07 March 2017

\section{References}

1. Shankaran S, Lester BM, Das A, Bauer CR, Bada HS, Lagasse L, et al. Impact of maternal substance use during pregnancy on childhood outcome. Semin Fetal Neonatal Med. 2007:12:143-50.

2. Hudak ML, Tan RC, Committee On Drugs; Committee On Fetus and Newborn; American Academy of Pediatrics. Neonatal drug withdrawal. Pediatrics. 2012;129:e540-60.

3. National Abandoned Infants Assistance Resource Center. Prenatal Substance Exposure. University of California Berkeley, Berkeley. 2012. https://taadas.s3. amazonaws.com/files/55dee01939610fa51 efb50856f4e9cb4-AlAFactSheet_ PrenatalSubExposure_2012.pdf. Accessed 1 Mar 2017.

4. Quesada O, Gotman N, Howell HB, Funai EF, Rounsaville BJ, Yonkers KA. Prenatal hazardous substance use and adverse birth outcomes. J Matern Fetal Neonatal Med. 2012;25:1222-7.

5. Rodriguez EM, Mofenson LM, Chang BH, Rich KC, Fowler MG, Smeriglio V et al. Association of maternal drug use during pregnancy with maternal HIV culture positivity and perinatal HIV transmission. AIDS. 1996;10:273-82.

6. Substance Abuse and Mental Health Services Administration. Results from the 2012 National Survey on Drug Use and Health: Summary of National Findings. Substance Abuse and Mental Health Services Administration, Rockville. 2013. NSDUH Series H-46, HHS Publication No. (SMA) 13-4795. http://archive.samhsa.gov/data/NSDUH/2012SummNatFindDetTables/ NationalFindings/NSDUHresults2012.pdf. Accessed 1 Mar 2017.

7. Jones HE, Kaltenbach K, Heil SH, Stine SM, Coyle MG, Arria AM, et al. Neonatal abstinence syndrome after methadone or buprenorphine exposure. N Engl J Med. 2010;363:2320-31.

8. Lupton C, Burd L, Harwood R. Cost of fetal alcohol spectrum disorders. Am J Med Genet C Semin Med Genet. 2004;127C:42-50.

9. Tuten M, Fitzsimons H, Chisolm MS, Nuzzo PA, Jones HE. Contingent incentives reduce cigarette smoking among pregnant, methadonemaintained women: results of an initial feasibility and efficacy randomized clinical trial. Addiction. 2012;107:1868-77.

10. Wilson GB, McGovern R, Antony G, Cassidy P, Deverill M, Graybill E, et al. Brief intervention to reduce risky drinking in pregnancy: study protocol for a randomized controlled trial. Trials. 2012;13:174

11. Ebrahim SH, Gfroerer J. Pregnancy-related substance use in the United States during 1996-1998. Obstet Gynecol. 2003;101:374-9.

12. Ruger JP, Lazar CM. Economic evaluation of drug abuse treatment and HIV prevention programs in pregnant women: a systematic review. Addict Behav. 2012;37:1-10

13. Yonkers KA, Forray A, Howell HB, Gotman N, Kershaw T, Rounsaville BJ, et al. Motivational enhancement therapy coupled with cognitive behavioral therapy versus brief advice: a randomized trial for treatment of hazardous substance use in pregnancy and after delivery. Gen Hosp Psychiatry. 2012;34:439-49.

14. Chang G, Wilkins-Haug L, Berman S, Goetz MA. The TWEAK: application in a prenatal setting. J Stud Alcohol. 1999;60:306-9.

15. Russell M, Martier SS, Sokol RJ, Mudar P, Jacobson S, Jacobson J. Detecting risk drinking during pregnancy: a comparison of four screening questionnaires. Am J Public Health. 1996;86:1435-9.

16. Fals-Stewart W, O'Farrell TJ, Freitas TT, McFarlin SK, Rutigliano P. The timeline followback reports of psychoactive substance use by drug-abusing patients: psychometric properties. J Consult Clin Psychol. 2000;68:134-44.

17. McLellan AT, Luborsky L, Woody GE, O'Brien CP. An improved diagnostic evaluation instrument for substance abuse patients. The Addiction Severity Index. J Nerv Ment Dis. 1980;168:26-33.

18. Xu X, Yonkers KA, Ruger JP. Costs of a motivational enhancement therapy coupled with cognitive behavioral therapy versus brief advice for pregnant substance users. PLoS One. 2014;9:e95264.

19. Thomson Reuters. Red Book: Pharmacy's Fundamental Reference (Red Book Drug Topics). 114th ed. Montvale, NJ: PDR Network, LLC; 2010.

20. U.S. Department of Labor, Bureau of Labor Statistics. Consumer Price Index. Available: http://www.bls.gov/cpi/. Accessed 7 May 2014

21. Sheehan DV, Lecrubier $Y$, Sheehan $\mathrm{KH}$, Amorim P, Janavs J, Weiller $E$, et al. The Mini-International Neuropsychiatric Interview (M.I.N.I.): the development and validation of a structured diagnostic psychiatric interview for DSM-IV and ICD-10. J Clin Psychiatry. 1998;59 Suppl 20:22-33.

22. Daley M, Argeriou M, McCarty D, Callahan Jr JJ, Shepard DS, Williams CN. The costs of crime and the benefits of substance abuse treatment for pregnant women. J Subst Abuse Treat. 2000;19:445-58.

23. Daley M, Shepard DS, Bury-Maynard D. Changes in quality of life for pregnant women in substance user treatment: developing a quality of life index for the addictions. Subst Use Misuse. 2005;40:375-94.

24. Jansson LM, Svikis D, Lee J, Paluzzi P, Rutigliano P, Hackerman F. Pregnancy and addiction. A comprehensive care model. J Subst Abuse Ttreat. 1996;13:321-9.

25. Svikis DS, Golden AS, Huggins GR, Pickens RW, McCaul ME, Velez ML, et al. Cost-effectiveness of treatment for drug-abusing pregnant women. Drug Alcohol Depend. 1997:45:105-13.

26. Daley M, Argeriou M, McCarty D, Callahan Jr JJ, Shepard DS, Williams CN. The impact of substance abuse treatment modality on birth weight and health care expenditures. J Psychoactive Drugs. 2001;33:57-66. 
27. Svikis D, McCaul M, Feng T, Stuart M, Fox M, Stokes E. Drug dependence during pregnancy. Effect of an on-site support group. J Reprod Med. 1998; 43:799-805.

28. Whiteman VE, Salemi JL, Mogos MF, Cain MA, Aliyu MH, Salihu HM. Maternal opioid drug use during pregnancy and its impact on perinatal morbidity, mortality, and the costs of medical care in the United States. J Pregnancy. 2014;2014:906723.

29. Fingar KR, Stocks C, Weiss AJ, Owens PL. Neonatal and Maternal Hospital Stays Related to Substance Use, 2006-2012. HCUP Statistical Brief \#193. July 2015. Agency for Healthcare Research and Quality, Rockville, MD. https:// hcup-us.ahrq.gov/reports/statbriefs/sb193-Neonatal-MaternalHospitalizations-Substance-Use.pdf. Accessed 1 Mar 2017.

30. Goler NC, Armstrong MA, Osejo VM, Hung YY, Haimowitz M, Caughey AB. Early start: a cost-beneficial perinatal substance abuse program. Obstet Gynecol. 2012:119:102-10.

31. Taillac C, Goler N, Armstrong MA, Haley K, Osejo V. Early start: an integrated model of substance abuse intervention for pregnant women. Perm J. 2007; 11:5-11.

Submit your next manuscript to BioMed Central and we will help you at every step:

- We accept pre-submission inquiries

- Our selector tool helps you to find the most relevant journal

- We provide round the clock customer support

- Convenient online submission

- Thorough peer review

- Inclusion in PubMed and all major indexing services

- Maximum visibility for your research

Submit your manuscript at www.biomedcentral.com/submit 